\title{
GAYA BAHASA PADA CERPEN "KUKILA (RAHASIA POHON RAHASIA)" DALAM KUMPULAN CERITA KUKILA KARYA M. AAN MANSYUR (SUATU KAJIAN STILISTIKA)
}

\author{
Reni Batmomolin \\ Mariana Lewier \\ Universitas Pattimura \\ e-mail: renibat20@gmail.com; analewier@gmail.com
}

\begin{abstract}
Abstrak: Gaya bahasa dalam karya sastra merupakan salah satu unsur yang menarik untuk dibahas. Penelitian ini berfokus pada analisis penggunaan gaya bahasa pada cerpen "Kukila" (Rahasia Pohon Rahasia) dalam Kumpulan Cerita Kukila karya M. Aan Mansyur dengan menggunakan Kajian Stilistika. Penulis melakukan penelitian ini dengan tujuan untuk dapat menunjukkan penggunaan gaya bahasa oleh pengarang dan makna setiap gaya bahasa yang ditemukan.

Penelitian ini merupakan penelitian kualitatif yang bersifat deskriptif. Data penelitian ini berupa kata, frasa, dan kalimat yang mengandung gaya bahasa. Teknik pengumpulan data menggunakan teknik baca, catat, dan kepustakaan, sementara teknik analisis data yang digunakan adalah Model Analisis Mengalir yang terdiri dari tiga alur kegiatan, yaitu reduksi, penyajian data, dan penarikan kesimpulan.

Hasil penelitian ini menunjukkan bahwa terdapat banyak gaya bahasa yang digunakan pengarang dalam cerpen tersebut, yaitu gaya bahasa perbandingan, gaya bahasa pertentangan, gaya bahasa pertautan, dan gaya bahasa perulangan. Penggunaan gaya bahasa dalam cerpen dimaksudkan untuk memperindah deskripsi cerita dan memperjelas makna yang ingin disampaikan pengarang.
\end{abstract}

Kata Kunci: Stilistika, Gaya bahasa, Cerpen 


\title{
LANGUAGE STYLES IN THE SHORT STORY "KUKILA (SECRET OF SECRET TREE) IN THE COLLECTION STORIES OF KUKILA BY M. AAN MANSYUR
} (A STYLISTIC STUDY)

\author{
Reni Batmomolin \\ Mariana Lewier \\ Pattimura University \\ e-mail: renibat20@gmail.com; analewier@gmail.com
}

\begin{abstract}
Language style in literary works is one of the interesting elements to be discussed. This study focuses on analyzing the use of language styles in the "Kukila" short story (Secret of Secret Tree) in the Collection Stories of Kukila by M. Aan Mansyur using the Stylistic Study. The author conducts this research with the aim of to explain the use of language styles by the author and the meaning of each style of language in the story.

This research is a descriptive qualitative research. This research data is in the form of words, phrases, and sentences that contain language style. Data collection techniques use the technique of reading, recording, and literature studies, while the data analysis technique used is Flow Analysis Models which consists of three activity lines, namely reduction, presentation of data, and making conclusions.
\end{abstract}

The results of this study indicate that there are many styles of language used by the authors in the short story, namely comparative language styles, opposing language styles, link language styles, and repetition language styles. The use of language styles in short stories is intended to beautify the description of the story and clarify the meaning that the author wants to convey.

Keywords: Stylistic Study, Language Style, Short Story 


\section{A. PENDAhuluan}

Karya sastra merupakan ungkapan pribadi manusia yang berupa pengalaman, pemikiran, perasaan, ide, semangat, keyakinan dalam suatu bentuk gambaran kehidupan yang dapat membangkitkan pesona dengan penggunaan bahasanya dan dilukiskan dalam bentuk tulisan. Menurut Sumardjo dan Sumaini (dalam Sumardjo 1984: 24), sastra adalah seni bahasa. Artinya, lahirnya sebuah karya sastra bertujuan agar pembaca dapat menikmati keindahan dalam sebuah karya sastra. Pada dasarnya, karya sastra sangat bermanfaat bagi kehidupan manusia, karena sastra dapat memberi kebenaran-kebenaran hidup walaupun dilukiskan dalam bentuk fiksi. Karya sastra juga dapat dijadikan pengalaman untuk berkarya sehingga siapapun bisa menuangkan isi hati dan pikiran ke dalam sebuah tulisan yang bernilai seni.

Prosa merupakan karangan yang bersifat menjelaskan secara terurai mengenai suatu masalah atau peristiwa. Prosa pada dasarnya terbagi atas novel, roman, dan cerita pendek. Salah satu jenis prosa yang akan penulis bahas dalam penelitian ini adalah cerita pendek. Cerita pendek atau cerpen merupakan salah satu karya sastra yang habis dibaca sekali duduk. Menurut Soeharianto (1982: 39), cerpen adalah wadah yang biasanya dipakai oleh pengarang untuk menyuguhkan sebagian kecil saja dari kehidupan tokoh yang menarik perhatian pengarang. Ia berpendapat bahwa cerpen tidak ditentukan oleh banyaknya halaman untuk mewujudkan cerita, melainkan lebih disebabkan oleh ruang lingkup permasalahan yang ingin disampaikan.

Istilah stilistika diserap dari bahasa Inggris stylistics yang diturunkan dari kata style atau gaya. Secara etimologi, istilah 'style', 'stail' atau 'gaya', yaitu cara yang khas dipergunakan oleh seseorang untuk mengutarakan atau mengungkapkan diri gaya pribadinya (Satoto, 2012: 34). Cara pengungkapan tersebut bisa meliputi setiap aspek kebahasaan (seperti diksi, penggunaan bahasa kias, bahasa figuratif, dan struktur kalimat).

Stilistika (stylistics) adalah ilmu yang meneliti tentang penggunaan bahasa dan gaya bahasa di dalam karya sastra (Sudjiman, 1993: 7). Secara teoritis, Verdonk (2002: 4) memandang stilistika sebagai analisis ekspresi yang khas dalam bahasa untuk mendeskripsikan tujuan dan efek tertentu. Bahasa yang digunakan dalam sebuah karya sastra adalah bahasa yang khas sehingga berbeda dari bahasa yang terdapat dalam karya non sastra. Karena itulah, bahasa sastra membutuhkan analisis yang khusus.

Tujuan stilistika, yaitu sebagai berikut. Pertama, stilistika untuk menghubungkan perhatian kritikus dalam apresiasi estetik dengan perhatian linguis dalam deskripsi linguistik. Kedua, untuk menelaah bagaimana unsur-unsur bahasa ditempatkan dalam menghasilkan pesan-pesan aktual lewat pola-pola yang digunakan dalam sebuah karya sastra. Ketiga, untuk menghubungkan intuisi-intuisi tentang makna-makna dengan pola-pola bahasa dalam teks (sastra) yang dianalisis. Keempat, untuk menuntun pemahaman yang lebih baik terhadap makna yang dikemukakan pengarang dalam karya-karyanya dan memberi apresiasi yang lebih terhadap kemampuan bersastra pengarangnya. Kelima, untuk menemukan prinsip- prinsip artistik yang mendasari pemilihan bahasa seorang pengarang. Keenam, kajian stilistika akan menemukan kiat pengarang dalam memanfaatkan 
kemungkinan yang tersedia dalam bahasa sebagai pengungkapan makna dan efek estetis bahasa. Jadi, tujuan dari stilistika adalah untuk merespon teks yang dianalisis sebagai sebuah karya sastra dan mengobservasi bahasa karya sastra tersebut (AlMaruf, 2012: 19-20).

Endraswara (2011: 74) mengemukakan langkah-langkah analisis yang perlu dilakukan dalam kajian stilistika adalah sebagai berikut:

1. Menetapkan unit analisis, misalkan berupa bunyi, kata, frasa, kalimat, bait, dan sebagainya.

2. Dalam puisi, analisis dapat berhubungan dengan pemakaian aliterasi, asonansi, rima, dan variasi bunyi yang digunakan untuk mencapai efek estetika.

3. Analisis diksi sangat penting karena ini tergolong wilayah kesastraan yang sangat mendukung makna dan keindahan bahasa. Kata dalam pandangan simbolis tentu akan memuat lapis-lapis makna. Kata akan memberikan efek tertentu dan menggerakan pembaca.

4. Analisis kalimat ditekankan pada variasi pemakaian dalam setiap kondisi.

5. Kajian makna gaya bahasa juga perlu mendapat tekanan tersendiri. Kajian makna hendaknya sampai pada tingkat majas, yaitu sebuah figurative language yang memiliki bermacam-macam makna.

\section{B. METODE PENELITIAN}

Penelitian ini termasuk penelitian kualitatif karena data yang dikumpulkan adalah deskripsi data. Deskripsi data meliputi penyusunan data dalam bentuk tampilan yang mudah terbaca secara lengkap.Penelitian ini bersifat deskriptif, yaitu memberikan gambaran secara jelas tentang bagaimana gaya bahasa dalam Cerpen "Kukila (Rahasia Pohon Rahasia)"karya M. Aan Mansyur.

Ciri penting dari penelitian kualitatif dalam kajian sastra antara lain: (1) peneliti merupakan instrumen kunci yang akan membaca secara cermat sebuah karya sastra, (2) penelitian dilakukan secara deskriptif, artinya terurai dalam bentuk kata-kata atau gambar jika diperlukan, bukan berbentuk angka, (3) lebih mengutamakan proses dibandingkan hasil, karena karya sastra merupakan fenomena yang banyak mengundang penafsiran, (4) analisis secara induktif, artinya dapat menemukan fakta-fakta yang lebih dari satu sesuai yang terdapat dalam data penelitian, dan (5) makna merupakan andalan utama, artinya untuk penganalisisan makna merupakan acuan utama untuk menemukan data (Endraswara, 2011:5).

Data penelitian ini berupa kata, frasa, dan kalimat-kalimat yang mengandung gaya bahasa dalam Cerpen Kukila (Rahasia Pohon Rahasia) karya M. Aan Mansyur. Sumber data dalam penelitian ini ialah teks Cerpen Kukila (Rahasia Pohon Rahasia) karya M. Aan Mansyur. Teknik pengumpulan data penelitian adalah teknik baca, teknik catat, dan Metode Kepustakaan.

Dalam penelitian ini, peneliti menggunakan teknik analisis data model mengalir, seperti yang dikemukakan oleh Milles dan Huberman (Sugiyono, 2010: 46). Model Analisis Mengalir mempunyai beberapa tahap yaitu: reduksi data, penyajian data, dan penarikan kesimpulan. 
Keabsahan data merupakan konsep penting yang diperbaharui dari konsep kesahihan (validitas) dan keandalan (realibilitas), yang disesuaikan dengan tuntutan pengetahuan, kriteria dan paradigmanya sendiri (Moleong, 2007: 321). Dalam penelitian ini teknik keabsahan data yang digunakan adalah teknik triangulasi, yaitu teknik pemeriksaan keabsahan data yang memanfaatkan sesuatu yang lain di luar data itu. Untuk keperluan pengecekan atau sebagai pembanding terhadap data yang diperoleh, yaitu triangulasi yang digunakan adalah metode dan teori. Langkah yang ditempuh adalah mencocokkan setiap data yang diperoleh dengan beberapa teori yang digunakan, kemudian mencocokkan kembali data-data yang dibaca dengan datadata yang dicatat.

\section{PEMBAHASAN}

Berdasarkan hasil penelitian, ditemukan 90 data yang mengandung berbagai jenis gaya bahasa sebagai berikut:

1. Gaya bahasa perbandingan yang di dalamnya terdapat empat jenis gaya bahasa, yaitu perumpamaan, metafora, personifikasi, dan antitetis.

2. Gaya bahasa pertentangan yang di dalamnya terdapat satu jenis gaya bahasa, yaitu hiperbola.

3. Gaya bahasa pertautan yang di dalamnya terdapat dua jenis gaya bahasa yaitu, elipsis dan inversi.

4. Gaya bahasa perulangan yang di dalamnya terdapat satu jenis gaya bahasa, yaitu repetisi.

Hasil penelitian ini akan dibahas secara berturut-turut dari gaya bahasa perbandingan, gaya bahasa pertentangan, gaya bahasa pertautan sampai dengan gaya bahasa perulangan. Pembahasan setiap gaya bahasa akan disertai dengan uraian contohnya.

\section{Gaya Bahasa Perbandingan \\ a. Perumpamaan}

Gaya bahasa perumpamaan adalah perbandingan dua hal yang pada hakikatnya berlainan dan sengaja dianggap sama.

1) Kau harus tahu, lupa adalah lahan subur kenangan-kenangan. Biarkan ia mengalir

seumpama sungai (K. 04-hlm. 10).

Kata ia yang dimaksudkan Mansyur dalam cerpen tersebut adalah kenangan. Makna kata kenangan secara denotatif adalah sesuatu yang membekas di ingatan, sedangkan kata sungai adalah aliran air yang besar (KBBI V). Pada data tersebut pengarang menggunakan kata seumpama, sehingga makna kata kenangan dianggap sama dengan frasa aliran sungai. Gaya bahasa perumpamaan dimanfaatkan Mansyur untuk melukiskan keadaan dari tokoh Kukila yang hendak melupakan kenangan atau masa lalunya.

2) Batang pohon mangga tetap selutut persis prasasti batu (K. 20-hlm. 13). 
Menurut KBBI V, batang pohon adalah bagian tumbuhan yang berada di atas, tempat tumbuhnya cabang dan ranting, sedangkan kata prasasti adalah piagam atau dokumen yang ditulis pada bahan yang keras dan tahan lama. Gaya bahasa perumpamaan dimanfaatkan Mansyur untuk menggambarkan batang pohon yang tinggal selutut itu kini menjadi pengingat bagi Kukila sehingga kenangan itu tidak dapat hilang dari ingatan Kukila. Kata persis digunakan sebagai kata yang menyatakan pembanding antara batang pohon dan prasasti batu.

3) Selebihnya aku hanya seorang gadis pemegang juara harapan pertama yang cerewet

\section{seperti burung nuri.}

Kata gadis sengaja dibandingkan dengan burung nuri, mengingat keduanya memiliki makna khusus. Menurut KBBI V, gadis adalah anak perempuan yang belum kawin, sedangkan burung nuri adalah burung kakak tua berbulu merah dan hijau (biru hitam), dapat menirukan suara manusia dan sebagainya. Gaya bahasa perumpamaan dimanfaatkan Mansyur untuk menggambarkan karakter tokoh Kukila yang cerewet atau banyak bicara, diibaratkan dengan burung nuri. Pada data tersebut, pengarang menggunakan kata seperti sehingga makna kata gadis sama dengan burung nuri.

\section{b. Metafora}

Metafora adalah pemakaian kata-kata bukan arti yang sebenarnya, melainkan sebagai lukisan yang berdasarkan persamaan atau perbandingan.

1) Sepasang mataku mencium punggungnya hingga ia hilang ditelan tikungan jalan dan kesedihanku tumbuh bertambah besar. (K. 05-hlm. 10)

Secara leksikal mencium mengandung makna 'menangkap bau dengan hidung' atau 'membau'. Pengalihan fungsi indera dari penciuman kepada penglihatan sengaja digunakan penulis pada klausa mataku mencium punggungnya untuk menimbulkan efek estetis pada kalimat tersebut. Makna sebenarnya dari kalimat di atas, yaitu sepasang mata Kukila menatap kepergian suaminya hingga tidak terlihat lagi.

2) Ia sibuk meletakkan neraka di seluruh penjuru. (K.19-hlm.13)

Kutipan di atas menunjukkan suasana di dalam rumah Mansyur yang seperti neraka. Kata neraka berarti alam akhirat tempat orang kafir dan orang durhaka mengalami siksaan dan kesengsaraan (KBBI V). Jadi, makna sebenarnya dari kalimat di atas adalah tokoh Kukila merasa hidupnya sangat tersiksa akibat kenangan buruk yang ditemuinya pada setiap sudut rumah. Segala macam siksaan disimpulkan dalam satu kata, yaitu neraka. Pengarang menggunakan kata neraka agar pembaca dapat beramajinasi tentang kesengsaraan hidup di neraka yang disandingkan dengan kehidupan sehari-hari Kukila yang terasa mengalami siksaan berat.

\section{c. Personifikasi}

Personifikasi adalah jenis gaya bahasa yang melekatkan sifat-sifat insani kepada barang-barang yang tidak bernyawa dan ide yang abstrak. Salah satu contohnya adalah kutipan berikut ini.

1) Pintu terbuka itu berkata: Rusdi, aku sepakat dengan kalimat-kalimatmu. (K. 06hlm. 10) 
Menurut KBBI V, pintu adalah tempat untuk masuk dan keluar yang terbuat dari

papan sebagai penutup rumah. Pengertian dasar ini kemudian digiring oleh penulis untuk mengibaratkan mulut sebagai sarana yang terbuka untuk menyampaikan atau mengeluarkan pesan atau isi hati. Pintu dimanfaatkan sebagai mitra bicara untuk berdialog oleh tokoh Rusdi yang merasa tidak ada lagi orang yang dapat diajak berbagi. Penulis juga memfasilitasi pesannya dengan memperlihatkan hati manusia itu ibarat pintu yang bisa terbuka atau pun tertutup sehingga untuk hati yang masih mau terbuka, pesan penting pun masih dapat didengarkan. Sebaliknya, hati yang tertutup akan sulit untuk menerima pesan sebaik apa pun maksud dan tujuannya.

2) September tidak pernah mau beranjak dari rumah (K.18-hlm. 13)

Makna kata September secara denotatif adalah bulan ke-9 menurut kalender tahun Masehi (maksimal 30 hari). Gaya bahasa personifikasi pada kalimat di atas dimanfaatkan Mansyur untuk menggambarkan keadaaan bulan September yang diibaratkan sebagai kenangan buruk yang tidak akan bisa hilang dari ingatan Kukila sampai kapan pun.

\section{d. Antitetis}

Antitetis adalah gaya bahasa yang mengadakan komparasi atau perbandingan antara dua antonim, yaitu kata-kata yang mengandung ciri semantik yang bertentangan. Kutipan berikut ini merupakan salah satu contoh gaya bahasa antitesis yang terdapat dalam cerpen "Kukila".

1) Kalau aku harus memilih, aku lebih suka menyanyi seperti burung pagi, dari pada menangis seperti burung malam. (K. 55-hlm. 31-32)

Menurut KBBI V, menyanyi adalah mengeluarkan suara bernada; berlagu (dengan lirik atau tidak), sedangkan menangis adalah melahirkan perasaan sedih (kecewa, menyesal, dan sebagainya) dengan mencucurkan air mata serta mengeluarkan suara. Pagi identik dengan "terang", sedangkan malam identik dengan "gelap". Pada waktu pagi seseorang dapat melihat banyak objek dengan jelas baik yang jauh mau pun dekat. Namun, saat malam penglihatannya terbatas kecuali jika ia menggunakan alat penerang. Pada waktu pagi seseorang memulai hari dengan harapan yang baru, begitu juga dengan Kukila. Kukila yang sakit hati karena ditinggalkan Pilang, memilih untuk tetap melanjutkan hidupnya dengan baik dari pada harus menangis meratapi kemalangannya. Gaya bahasa antitetis pada data di atas sengaja dimanfaatkan Mansyur untuk menunjukkan dua hal yang saling bertentangan tetapi nyata dalam kehidupan manusia. Kata menyanyi dan menangis merupakan dua hal yang bertentangan seperti halnya benar-salah, senang-sedih, gelapterang, dan sebagainya merupakan pasangan yang selalu ada dalam kehidupan.

\section{Gaya Bahasa Pertentangan}

\section{Hiperbola}

Hiperbola adalah gaya bahasa yang mengandung pernyataan yang berlebihlebihan, jumlahnya, ukurannya, atau sifatnya, dengan maksud memberi penekanan pada 
suatu pernyataan atau situasi untuk memperhebat, meningkatkan kesan, dan pengaruhnya.

1) Memilih dan memilah kata tepat membutuhkan waktu bertahun-tahun. (K. 01-hlm.

7)

Mansyur sebagai penulis sengaja menggunakan kata ulang bertahun-tahun untuk menggambarkan dua hal. Pertama, proses memilih dan memilah kata yang tepat sebagai proses yang tidak mudah. Kedua, proses yang tidak mudah itu memerlukan waktu yang relatif lebih panjang. Dengan kata ulang bertahun-tahun yang memiliki makna gramatikal

'banyak tahun', penulis berupaya memberi penekanan yang penting pada aspek memilih dan memilah kata sehingga perlu mendapat perhatian yang saksama.

2) Air mataku akan semakin deras mengalir (K. 30-hlm. 17)

Mansyur menggunakan klausa "air mataku semakin deras mengalir" untuk menggambarkan air mata yang tidak berhenti menetes, bahkan mengalir sangat banyak. Hal ini menunjukkan kesedihan atau rasa penyesalan yang mendalam, yang tidak dapat dihilangkan.

\section{Gaya Bahasa Pertautan \\ a. Elipsis}

Elipsis ialah gaya bahasa yang di dalamnya dilaksanakan pembuangan atau proses penghilangan kata atau kata-kata yang memenuhi bentuk kalimat berdasarkan tata bahasa.

1) Kata ayah, aku seekor burung yang cantik dan lincah. (K. 50-hlm. 29)

Data tersebut merupakan gaya bahasa elipsis, karena terdapat penanggalan atau penghilangan kata yang menjadikan struktur kalimat tersebut tidak utuh. Pada frase aku seekor burung, terdapat penghilangan konjungsi yang menyebabkan kalimat tersebut tidak berterima. Kalimat tersebut dapat dikatakan utuh jika ditambahkan kata "adalah", maka kalimat tersebut menjadi Kata ayah, aku adalah seekor burung yang cantik dan lincah.

Dengan demikian, konjungsi pada kalimat yang dielipsiskan pada data tersebut membuat kalimat menjadi pendek dan pesan yang dikemukakan menjadi fokus. Hal itu dilakukan Mansyur untuk menegaskan arti nama Kukila menurut kesusastraan klasik yang artinya burung. Penulis memanfaatkan kecantikan dan kelincahan burung, untuk menggambarkan masa kecil Kukila, sehingga perlu mendapat perhatian saksama dari pembaca.

\section{b. Inversi}

Inversi adalah gaya bahasa yang merupakan permutasi atau perubahan urutan unsur- unsur kontruksi sintaksis. Artinya, gaya bahasa ini dapat memanfaatkan struktur klausa atau kalimat yang tidak lazim karena fungsi predikat $(\mathrm{P})$ diposisikan di depan fungsi subjek (S), ataupun struktur frasa yang berkonstruksi MD (yang Menerangkan mendahului yang Diterangkan).

1) September tiba selalu dengan kemarau tajam. (K. 10-hlm. 11) 
Kalimat tersebut mengandung gaya bahasa inversi, karena terdapat perubahan urutan kata pada frasa tiba selalu yang lazim berkonstruksi selalu tiba. Gaya ini dimaksudkan untuk memprioritaskan tibanya bulan September yang sangat tidak dinantikan karena bulan itu identik dengan musim kemarau yang sangat panas yang tidak disukai Kukila.

Di samping kondisi alam yang dipotret dalam gaya inversi ini menyangkut bulan September, tetapi juga kenangan tidak enak bagi Kukila harus berpisah dari suaminya, dan ditinggalkan anak-anaknya pada bulan yang sama.

\section{Gaya Bahasa Perulangan Repetisi}

Repetisi adalah gaya bahasa yang mengandung pengulangan kata atau kelompok kata yang sama.

1) Ia harus pulang menyulam kembali sepinya di rumah, seperti kemarin, seperti dua hari lalu, seperti bulan lalu, tahun-tahun lalu-seperti besok, dan seterusnya. (K. 02-hlm. 7)

Pengulangan kata seperti dan lalu pada frasa "seperti kemarin, seperti dua hari lalu, seperti bulan lalu, tahun-tahun lalu-seperti besok" merupakan gaya bahasa repetisi yang berfungsi sebagai penegasan deskripsi cerita agar makna yang disampaikan Mansyur dapat ditangkap lebih jelas oleh pembaca.

Pemilihan dan penggunaan repetisi dalam Cerpen "Kukila Rahasia Pohon Rahasia" cukup dominan pada deskripsi cerita. Mansyur membuat penekananpenekanan dengan kata yang diulang-ulang dengan maksud memperindah deskripsi cerita, dan menonjolkan durasi waktu yang panjang, yang harus dilalui oleh tokoh Kukila dalam penderitaannya yang disebabkan oleh rasa kesepian.

2) Selain kehilangan dirimu, aku kehilangan harga diri (K. 65-hlm. 44)

Repetisi kata kehilangan pada frasa "selain kehilangan dirimu”, dan klausa aku kehilangan harga diri" berfungsi menegaskan bahwa Rusdi benar-benar telah kehilangan sesuatu yang penting dalam hidupnya. Ia telah kehilangan seseorang yang sangat ia cintai, bahkan harga dirinya ikut menghilang bersama dengan cintanya. Kehilangan cinta dan harga diri dapat membuat seseorang menganggap dirinya tidak berguna bagi siapa pun.

\section{KESIMPULAN}

Berdasarkan kajian pustaka, paparan, data dan pembahasan yang telah dilakukan dapat ditarik kesimpulan bahwa yang terdapat gaya bahasa dalam Cerpen "Kukila (Rahasia Pohon Rahasia)" dalam Kumpulan Cerita Kukila adalah sebanyak 90 data berupa kalimat-kalimat yang mengandung gaya bahasa perbandingan, gaya bahasa pertentangan, gaya bahasa pertautan, dan gaya bahasa perulangan. Gaya bahasa perbandingan yang di dalamnya terdapat

4 jenis gaya bahasa, yakni perumpamaan sebanyak 37 gaya bahasa, metafora sebanyak 15 gaya bahasa, personifikasi sebanyak 10 gaya bahasa, dan antitetis sebanyak 4 gaya bahasa. Gaya bahasa pertentangan yang di dalamnya terdapat 1 jenis gaya bahasa, yakni hiperbola sebanyak 13 gaya bahasa. Gaya bahasa pertautan yang di dalamnya terdapat 2 jenis gaya bahasa, yaitu elipsis 1 gaya bahasa dan inversi 
sebanyak 2 gaya bahasa. Gaya bahasa perulangan yang di dalamnya terdapat 1 jenis gaya bahasa, yakni repetisi sebanyak 8 gaya bahasa.

Gaya bahasa yang sering muncul dalam cerpen "Kukila (Rahasia Pohon Rahasia) karya M. Aan Mansyur adalah gaya bahasa perbandingan, yaitu gaya bahasa perumpamaan. Dalam gaya bahasa perumpamaan yang telah dianalisis, penulis menemukan penggunaan kata seperti, seumpama, persis, bagai, semata, serupa, dan tidak ubahnya yang berfungsi sebagai pembanding untuk menyamakan dua hal yang pada hakikatnya berlainan.

Kajian stilistika terhadap cerpen "Kukila" ini diharapkan dapat membantu pemahaman makna cerpen tersebut dan dapat memperlihatkan bagaimana kekhasan gaya bahasa yang digunakan sang pengarang, yakni M.Aan Mansyur. Salah satu kekhasan yang dapat diperoleh dari M. Aan Mansyur adalah penggunaan kata persis dalam gaya bahasa perumpaan yang merupakan salah satu kata pembanding yang umumnya digunakan oleh penutur bahasa dari Indonesia Timur.

\section{DAFTAR PUSTAKA}

Alwi, Hasan, dkk. 2005. Tata Bahasa Baku Bahasa Indonesia. Yogyakarta: Balai Pustaka.

Al-Maruf, Ali Imron. 2012. Kajian Stilistika Perspektif Kritik Holistik. Surakarta: UNS Press.

Aminuddin. 1995. Stilistika: Pengantar Memahami Bahasa dalam Karya Sastra. Semarang: IKIP Semarang Press.

Atmazaki. 2005. Ilmu Sastra: Teori dan Terapan. Padang: Citra Budaya Indonesia.

Badan Pengembangan dan Pembinaan Bahasa. 2016. Kamus Besar Bahasa Indonesia Edisi Kelima (KBBI V). Jakarta. (Aplikasi Luring)

Djajasudarma, T. Fatimah. 1993. Metode Linguistik: Ancangan Metode Penelitian dan Kajian. Jakarta: Eresco.

Endraswara, Suwardi. 2011. Metode Penelitian Sastra: Epistemologi, Model, Teori, dan Aplikasi. Jakarta: CAPS.

Indriani, Sri. 2015. "Teori Stilistika (Pengantar Ringkas)", ditulis dalam blog Teach and Learn, diakses pada 31 Januari 2017.

Keraf, Gorys. 1984. Diksi dan Gaya Bahasa. Jakarta: PT. Gramedia Pustaka Utama. Mansyur, M. Aan. 2012. Kumpulan Cerita Kukila. Jakarta: PT. Gramedia Pustaka Utama.

Moleong, Lexy J. 2007. Metodologi penelitian kualitatif. Bandung: Remaja Rosdakarya.

Nabila, Firli Athiah. 2015. "Cerita Aan Mansyur, Sang Penyair di Balik Puisi Indah di AADC 2", ditulis dalam blog Liputan 6.com, diakses pada 4 Februari 2017.

Natawidjaja, P. Suparman. 1986. Apresiasi Stilistika. Jakarta: Intermasa.

Nurgiyantoro, Burhan. 2007. Teori Pengkajian Fiksi. Yogyakarta: Gadjah Mada University Press.

Priyatni, Endah Tri. 2012. Membaca Sastra dengan Ancangan Literasi Kritis. Jakarta: Bumi Aksara. 
Gaya Bahasa Pada Cerpen "Kukila (Rahasia Pohon Rahasia)" dalam Kumpulan Cerita Kukila Karya. M. Aan Mansyur (Suatu Kajian Stilistika)

Ratna, Nyoman Kutha. 2009. Stilistika: Kajian Puitika, Bahasa, Sastra, dan Budaya. Yogyakarta: Pustaka Pelajar.

Semi, M. Atar. 2008. Stilistika Sastra. Padang: UNP Press.

Soeharianto, S. 1982. Dasar-dasar Teori Sastra. Surakarta: Widya Duta. Sudiro, Satoto. H. 2012. Stilistika. Surakarta: Penerbit Ombak Dua.

Sudjiman, Panuti. 1993. Bunga Rampai Stilistika. Jakarta: Grafiti.

Sumardjo, Jakob. 1984. Memahami Kesusastraan. Bandung: ALUMNI.

Sugiyono, 2010. Memahami Penelitian Kualitatif. Bandung.

Tarigan, Henry Guntur. 1984. Prinsip-prinsip Dasar Sastra. Bandung: Penerbit Angkasa.

Tarigan, Henry Guntur. 1989. Pengajaran Gaya Bahasa. Bandung: Penerbit Angkasa. Verdonk, Peter. 2002. Stylistics. New York: Oxford University Press.

Wahyu, 2017. "Jenis-jenis Cerpen Berdasarkan Panjang dan Alirannya", ditulis dalam blog PustakaIndo, diakses pada 2 Februari 2017.

Zed, Mestika. 2008. Metode Penelitian Kepustakaan. Jakarta: Yayasan Obor Indonesia. 
Gaya Bahasa Pada Cerpen "Kukila (Rahasia Pohon Rahasia)" dalam Kumpulan Cerita Kukila Karya. M. Aan Mansyur (Suatu Kajian Stilistika) 